\title{
O PVC matéria-prima para a indústria de plásticos
}

O desenvolvimento da produção industrial de PVC, verificado a partir de 1930, resultou basicamente de dois tipos de razס̄es: por um lado, a disponibilidade de matérias-primas para o fabrico do monómero cloreto de vinilo: 0 acetileno (inicialmente), o etileno (em seguida), e o cloro, factores que permitiram a produção do PVC a um preço competitivo, e por outro, o desenvolvimento das tecnologias de composição e de processamento (extrusão, injecção e calandragem principalmente) que vieram resolver os iniciais problemas derivados da alta viscosidade do polímero e da sua fraca estabilidade térmica.

Em Portugal o fabrico de resinas de PVC iniciou-se em 1963 na fábrica da Cires em Estarreja; paralelamente foi instalada uma unidade de síntese de cloreto de vinilo a partir do acetileno (também aí produzido) e do gás clorídrico (proveniente de fábrica vizinha).

Este processo, usualmente designado de carboquímico, consiste na reacção de adição de gás clorídrico ao acetileno em reactor multubular de leito catalítico, e na lavagem e destilação do cloreto de vinilo obtido. A produção da Cires duplicou entre 1963 e 1970, passando de 5000 ton/ano para 10000 ton/ano, mantendo-se desde então em valores entre 10 e $12 \mathrm{mil}$ ton/ano. O interesse industrial deste processo de fabrico está relacionado com o preço do acetileno - obtido a partir do carboneto de cálcio e este por sua vez a partir do carbonato de cálcio - e em particular com a relação deste preço, com o preço do etileno.

A polimerização do cloreto de vinilo é realizada em reactores tipo autoclave por mecanismos de radicais livres num processo designado de suspensão - para obter o PVC-S - ou de emulsão - para o PVC-E -, ambos (suspensão e emulsão) em água, que através de agentes adequados, sustém as gotículas de monómero e promove a transferência de calor; finalizada a polimerização, o PVC-S formado é separado da água por centrifugação e seco em secador de leito fluidizado, e o PVC-E é directamente seco em secador tipo spray. A diferença fundamental das resinas obtidas por estes dois processos é no diâmetro das partículas: entre 75 e $250 \mu \mathrm{m}$ para o suspensão e cerca de $1 \mu \mathrm{m}$ para o emulsão; o tipo de aplicaçð̃es é em consequência completamente distinto.

A produção de resinas de suspensão - com o nome comercial de VICIR-S - que foi no primeiro ano de fabrico, em 1963, de 1100 ton., era em 1970 de 11500 ton., em 80 de cerca de 40000 ton. e foi em 85 de aproximadamente de 48000 ton. A produção de resinas de emulsão - VICIR E - cujo fabrico se iniciou em finais de 82, é de cerca de 5000 ton/ano.

Qualquer que seja o processo de fabrico, as resinas de PVC necessitam, para a subsequente transformação, de serem aditivadas num processo que se designa por composição; basicamente podem distinguir-se os materiais ou os artigos de base PVC, em flexíveis e rígidos, consoante na composição foi ou não incorporado um plastificante; o efeito do plastificante - em geral um ftalato - é o de baixar a temperatura de transição vítrea permitindo obter um artigo maleável à temperatura ambiente.

As resinas de PVC-E com o diâmetro referido, são sempre processadas com plastificante, constituindo dispersర̃es do PVC no plastificante; estas dispersð̃es são sistemas líquidos à temperatura ambiente, pelo que são especialmente indicadas para processamentos por endução (coating) ou por outros processos de revestimento, já que se "espalham" com muita facilidade. Em Portugal a principal aplicação é o fabrico de napas vinílilas (o couro artificial) podendo no entanto referir-se que na Europa uma importante aplicação é a alcatifa vinílica.

O comportamento reológico das dispersð̃es de PVC, usualmente designadas como plastisois ou simplesmente pastas de PVC, é - em termos de qualidade - a característica mais importante; cite-se como exemplo o fabrico de papel de parede vinílico, cuja velocidade de produção é frequentemente superior a $100 \mathrm{~m} /$ minuto, sendo portanto necessária uma pasta com comportamento pseudoplástico (isto é diminuição da viscosidade com o aumento da velocidade) e com um muito baixo valor de viscosidade para elevadas velocidades de corte.

$\mathrm{O}$ diâmetro das partículas do PVC, e em particular a distribuição dos diâmetros, em simultâneo com o nível de viscosidade do plastificante e o modo de interacção deste com a resina, são os parâmetros que determinam o comportamento reológico do plastisol. As resinas VICIR-E são em geral pseudoplásticas e possibilitam uma apreciável variação de níveis de viscosidade de acordo com o requerido para o tipo de processamento.

No PVC-S, em geral, a distribuição de tamanhos é aproximadamente idêntica, sendo o peso molecular médio, usualmente referenciado pelo "valor K", e a estrutura da partícula (isto é, se é porosa ou vítrea), os factores principais que caracterizam a resina. $\mathrm{O}$ peso molecular determina as propriedades mecânicas do produto final e a temperatura de processamento necessária para completa fusão do polímero; a porosidade determina a facilidade com que a resina absorve o plastificante. Em geral as resinas mais porosas têm mais elevado peso molecular, sendo apenas utilizadas para fabrico de materiais plastificados.

Como matéria-prima para a indústria dos plásticos, o 
policloreto de vinilo é o polímero mais versátil e com a mais variada gama de aplicaçð̃es que actualmente se fabrica; mediante a utilização de aditivos específicos e utilizando tecnologias apropriadas, podem obter-se das resinas de PVC produtos cujo comportamento e características são extremamente diferenciadas; assim, do tubo de mangueira para rega ao tubo rígido de pressão, à garrafa de óleo ou de água mineral, aos discos, às réguas de estore, ao revestimento de cabos eléctricos, às napas, etc. encontra-se uma diversidade de produtos cujo constituinte básico é o PVC. Em Portugal o tipo de aplicaçð̃es é caracterizado no quadro seguinte:

\begin{tabular}{|l|cr|rr|}
\hline & \multicolumn{2}{|c|}{1979} & \multicolumn{2}{c|}{1985} \\
\cline { 2 - 6 } & Kton* & $\%$ & Kton* & $\%$ \\
\hline PVC rígido & 25 & 57 & 36,5 & 65 \\
\hline Tubagem & 9.8 & 22 & 20,5 & 37 \\
Garrafas & 5.8 & 13 & 9,5 & 17 \\
Perfis & 6.8 & 15 & 4,8 & 8 \\
Outros & 2.3 & 6 & 1,7 & 3 \\
\hline PVC flexível & 19 & 43 & 19,5 & 35 \\
\hline Cabos eléctricos & 4.1 & 9 & 4,3 & 8 \\
Calçado & 4.0 & 9 & 3,7 & 7 \\
Tubagem e Perfis & 2.0 & 5 & 2,5 & 4 \\
Filme & 2.5 & 6 & 2,0 & 4 \\
Napas e Outros & 6.2 & 14 & 7,0 & 12 \\
\hline TOTAL GERAL & 44 & - & 56 & - \\
\hline
\end{tabular}

* Kilotoneladas.
À semelhança de outros materiais plásticos, o PVC tem um vasto campo de aplicaçðes ligado ao sector da construção civil; em média pode dizer-se que $20 \%$ das aplicaçð̋es das matérias plásticas se destinam a este sector; contudo no PVC tal percentagem atinge cotas de $60 \%$ ou mesmo $70 \%$; daqui resulta uma efectica sensibilidade às perturbaçð̄es do sector, mas por outro lado um potencial e quase inexgotável campo de aplicaçð̃es. E cabe lembrar que em Portugal não foi ainda explorado convenientemente o campo dos perfis rígidos para janelas, área de aplicação que pelas características inerentes ao PVC - baixa condutividade térmica, resistência à corrosão e ausência de apodrecimento - e pelo volume do mercado, é particularmente relevante em termos de aplicaçðes potenciais.

O PVC cuja produção industrial se desenvolveu como se referiu a partir de 1930 , é, mercê da sua versatilidade funcional e da sua particular e única característica relativamente a outros termoplásticos de grande consumo, de permitir o escoamento de excedentes em etileno e em cloro, uma matéria-prima indispensável, prevendo-se que em Portugal o consumo atinja as 90 mil toneladas no final da década, e estimando-se o aumento do consumo global na Europa entre 1980 e 1990 em $1 \%$ o que corresponde a um total no final da década de cerca de 4 milhðes de toneladas, colocando o PVC, como aliás já acontece desde 1981, o termoplástico de maior consumo, quando isoladamente comparado com qualquer dos polietilenos, com o polipropileno ou com o poliestireno. 